\title{
Modelization and Optimization of Quality Characteristics of Pork Treated Various Hydrostatic Pressure Conditions
}

\author{
Geun-Pyo Hong ${ }^{1}$, Ji-Yeon Chun ${ }^{1}$, Si-Kyung Lee, and Mi-Jung Choi* \\ Department of Molecular Biotechnology, Konkuk University, Seoul 143-701, Korea \\ ${ }^{1}$ Department of Food Science and Biotechnology of Animal Resources, Konkuk University, Seoul 143-701, Korea
}

\begin{abstract}
In this study, the effects of physical parameters (30-270 MPa of pressure, 3-57 min of time, and 1-49 ${ }^{\circ} \mathrm{C}$ of temperature) on pork quality were investigated. Response surface methodology was used in order to monitor and model the changes in pork quality under varied pressure conditions. As quality characteristics, shear force, water holding capacity (WHC) and the CIE color of pork were measured, and optimum pressure conditions were evaluated by statistical modeling. Pressure improved the WHC of pork at relatively low temperature $\left(<25^{\circ} \mathrm{C}\right)$; however, the opposite occurred with increasing temperature. Although pressure and temperature affected the tenderness of the meat, interaction effects among variations were not observed. At pressure levels higher than $200 \mathrm{MPa}$, the color of pork differed markedly from that of the untreated controls. In particular, differential scanning calorimetry (DSC) revealed marked evidence of myosin denaturation. The present study demonstrates that pork quality varies depending on pressure conditions.
\end{abstract}

Key words: pressure, pork meat, quality change, modeling, response surface methodology

\section{Introduction}

Of all the attributes of meat quality, tenderness is rated by consumers as the most important. Meat can be physically or chemically tenderized by one of several artificial means. High hydrostatic pressurization is a newly developed technique for tenderizing meat (Suzuki et al., 1993). The variation in meat tenderness depends mainly on the post-mortem timing of high-pressure application. Macfarlane (1973) first proposed the use of high-pressure treatment to tenderize pre-rigor meat. The effects of pressurization on post-rigor muscle tenderness may vary depending on treatment conditions, particularly pressurization temperatures (subzero, refrigerated, and high).

Meat color is an important indicator of freshness and wholesomeness (Mancini and Hunt, 2005); however, highpressure treatment has been shown to trigger meat discoloration. On the other hand, Cheah and Ledward (1997) demonstrated that meat blooms more readily and retains its red color longer after pressurization. Jung et al. (2003)

\footnotetext{
*Corresponding author: Mi-Jung Choi, Department of Molecular Biotechnology, Konkuk University, Seoul 143-701, Korea. Tel: 82-2-450-3048, Fax: 82-2-455-1044, E-mail: choimj@konkuk. ac.kr
}

proposed that the increased redness of pressurized meat may be due to activation of the enzymatic system that is implicated in metmyoglobin reduction, thus resulting in a decrease in metmyoglobin content. In our previous study, we discovered that pressure-assisted frozen meat exhibited less redness with increasing pressure levels, whereas increasing pressure on refrigerated $\left(4^{\circ} \mathrm{C}\right)$ meat resulted in more redness.

By investigating the physico-chemical properties of pressurized meat, we found that the results lacked consistency mainly because different operational conditions were applied for several parameters, including pressure, temperature, and holding time. The overall physical quality of meat can be evaluated by its tenderness, water-holding capacity (WHC), and color. In this study, we explored the effects of varied pressurization conditions on meat quality, and we optimized pressure conditions to minimize the quality drawback caused by pressurization.

\section{Materials and Methods}

\section{Materials}

Porcine longissimus dorsi muscles ( $\mathrm{pH}$ 5.4-5.6) were selected randomly from 6 carcasses from a local abattoir $24 \mathrm{~h}$ post-mortem. All visible fat and connective tissue 
was trimmed, and the meat was cut into a rectangular shape $(2 \times 4 \times 10 \mathrm{~cm})$. All samples were obtained from the center of the muscle with its axis parallel to the fiber direction; the obtained samples were then vacuum-sealed in a poly-nylon pouch. All samples were stored in a refrigerator $\left(4^{\circ} \mathrm{C}\right)$ prior to pressurization, which took place within $24 \mathrm{~h}$. All chemicals used in this study were of analytical grade.

\section{High-pressure treatment}

High-pressure treatments were performed in a lab-scale high pressure unit as detailed in our previous study (Hong et al., 2005). Briefly, the device consisted of 6 pressure vessels with a working volume of $300 \mathrm{~mL}$, an air compressor (S-40; Seowon Compressor Co., Korea), a pressure intensifier (K2; Haskel International Inc., USA), a temperature controller (FP80; Julabo Labortechinik GmbH, Germany), and a data logger (MV104; Yokogawa Co., Japan). Ethanol was used as the compression fluid. The compression and depression rates were 2.4 and $23 \mathrm{MPa} / \mathrm{s}$, respectively. To model the changes in quality, meat was pressurized at varying pressure levels (30-270 $\mathrm{MPa})$, holding times (3-57 $\mathrm{min}$ ), and initial temperatures (1$49^{\circ} \mathrm{C}$ ) as shown in Table 1 . Holding time was calculated from the point at which the targeted pressure level was reached. After pressurization was completed, samples were stored at $4^{\circ} \mathrm{C}$ until analysis.

To optimize the processing conditions, we superimposed all quality contour maps and estimated the best pressurization conditions by examining the regions in which the pork quality demonstrated minimum difference from the quality of the untreated controls. To estimate the relationship between regression models and the actual quality scores, we pressurized the pork samples at the estimated optimized conditions using the same equipment described above and compared the quality characteristics with the scores obtained from the regression models.

\section{Assessment of water-holding capacity (WHC)}

WHC was determined by a centrifugal method. Approximately $1 \mathrm{~g}$ of meat was weighed and added to a centrifuge tube with gauze (an absorbent). The samples were centrifuged for $10 \mathrm{~min}$ at $1,000 \mathrm{~g}$ by using an automatic refrigerated centrifuge (RC-3; Sorvall Co., USA) at $4^{\circ} \mathrm{C}$. After centrifugation, the meat was removed from the tube and weighed before and after drying. WHC measurements were expressed as the percentage of moisture remaining in the meat and were conducted in triplicate.
Table 1. Experimental design for modeling the characteristics of pork quality following various high-pressure treatments

\begin{tabular}{cccccccc}
\hline \hline & \multicolumn{3}{c}{ Coded unit } & & \multicolumn{3}{c}{ Uncoded value } \\
\cline { 2 - 3 } \cline { 6 - 7 } Treatments & $\mathrm{X}_{1}$ & $\mathrm{X}_{2}$ & $\mathrm{X}_{3}$ & $\begin{array}{c}\text { Pressure } \\
(\mathrm{MPa})\end{array}$ & $\begin{array}{c}\text { Time } \\
(\mathrm{min})\end{array}$ & $\begin{array}{c}\text { Temperature } \\
\left({ }^{\circ} \mathrm{C}\right)\end{array}$ \\
\hline 1 & -1.5 & 0 & 0 & & 30 & 30 & 25 \\
2 & -1 & -1 & -1 & & 70 & 12 & 9 \\
3 & -1 & -1 & 1 & & 70 & 12 & 41 \\
4 & -1 & 1 & -1 & & 70 & 48 & 9 \\
5 & -1 & 1 & 1 & & 70 & 48 & 41 \\
6 & 0 & -1.5 & 0 & & 150 & 3 & 25 \\
7 & 0 & 0 & -1.5 & & 150 & 30 & 1 \\
8 & 0 & 0 & 0 & & 150 & 30 & 25 \\
9 & 0 & 0 & 0 & & 150 & 30 & 25 \\
10 & 0 & 0 & 0 & & 150 & 30 & 25 \\
11 & 0 & 0 & 0 & & 150 & 30 & 25 \\
12 & 0 & 0 & 0 & & 150 & 30 & 25 \\
13 & 0 & 0 & 0 & & 150 & 30 & 25 \\
14 & 0 & 1.5 & 0 & & 150 & 57 & 25 \\
15 & 0 & 0 & 1.5 & & 150 & 30 & 49 \\
16 & 1 & -1 & -1 & & 230 & 12 & 9 \\
17 & 1 & -1 & 1 & 230 & 12 & 41 \\
18 & 1 & 1 & 1 & 230 & 48 & 41 \\
19 & 1 & 1 & -1 & 230 & 48 & 9 \\
20 & 1.5 & 0 & 0 & 270 & 30 & 25 \\
\hline & & & & & &
\end{tabular}

\section{Determination of shear force}

After receiving thermal treatment for $30 \mathrm{~min}$ at $75^{\circ} \mathrm{C}$, each sample was cooled under cold running water for 5 min, tempered at ambient for $1 \mathrm{~h}$, and then cut into strips $1 \mathrm{~cm}$ in diameter, $4 \mathrm{~cm}$ in length, and parallel to the longitudinal orientation of the muscle fibers. Each strip was sheared using a digital gauge (DPS-20; IMADA Co., Japan) with the head speed maintained at $60 \mathrm{~mm} / \mathrm{min}$. The shear force was measured at least 24 times.

\section{Instrumental color measurement}

Color was measured with a color reader (CR-10; Konica Minolta Sensing, Inc., Japan) that had been calibrated with a white standard plate $\left(L^{*}=97.83, a^{*}=-0.43, b^{*}=\right.$ +1.98 ). The CIE $L^{*}, a^{*}$, and $b^{*}$ values served as indicators of lightness, redness, and yellowness, respectively. The sample was oxygenated for $10 \mathrm{~min}$ after pressure treatment, and 6 measurements were obtained from each surface of the sample. The total color difference $(\Delta E)$ was calculated numerically by comparing the color of the treated samples and untreated controls by using the following equation.

$$
\Delta E=\sqrt{\Delta L^{* 2}+\Delta a^{* 2}+\Delta b^{* 2}}
$$




\section{Differential scanning calorimetry}

Differential scanning calorimetry (DSC) was performed on a differential scanning calorimeter (DSC200F3; NetzschGeraetebau GmbH, Germany). Indium was used to calibrate the instrument. Approximately $20 \mathrm{mg}$ of sample, pressurized at optimized conditions, was weighed, placed in an aluminum pan, and heated from $20^{\circ} \mathrm{C}$ to $100^{\circ} \mathrm{C}$ at a rate of $5^{\circ} \mathrm{C} / \mathrm{min}$. An empty pan was used as reference, and an additional scan from $20^{\circ} \mathrm{C}$ to $100^{\circ} \mathrm{C}$ was conducted with all samples.

\section{Statistical analysis}

Response surface methodology (RSM) was adopted for designing the mathematical model using SAS 9.1 (SAS Institute Inc., Cary, NC, USA). We adopted the central composite design to study the combined effect of 3 independent variables, i.e., pressure, holding time, and temperature (coded as $\mathrm{X}_{1}, \mathrm{X}_{2}$, and $\mathrm{X}_{3}$, respectively). The complete design consisted of 20 groups. To estimate pure error, we performed 6 replications of the center point for each group (Table 1). Each parameter was represented by a second-order polynomial expression as shown below.

$$
Y=\beta_{o}+\sum_{i}^{k} \beta_{i} X_{i}+\sum_{i}^{k} \beta_{i i} X_{i}^{2}+\sum_{i<j}^{k} \beta_{i j} X_{i} X_{j}
$$

$Y$ represents the response that was estimated from the replicate measurements. $\beta_{0}, \beta_{i}, \beta_{i i}$, and $\beta_{i j}$ represent constant, linear, quadratic, and interaction coefficients, respectively. $X_{i}$ and $X_{j}$ represent independent variable levels, and $k$ represents the number of independent variables.

The data obtained from the optimization experiments were analyzed by one-way analysis of variance (ANOVA) using the SAS statistical program 9.1. The means were compared using Duncan's Multiple Range tests $(p<0.05)$.

\section{Results and Discussion}

\section{Statistical analysis}

To model pork quality under high-pressure treatment, response surface methodology was employed to determine WHC, shear force, and CIE color characteristics. Table 2 displays the response from each treatment. The regression coefficients of response from dependent variables are provided in Table 3. The results show that the generated regression models both effectively explained the data variation and indicated signification correlation between the independent variables and responses. All models demonstrated statistical significance at the 0.001 level without lack-of-fit and $R$-square values above 0.7 ,
Table 2. Experimental pork-quality response to various highpressure treatments

\begin{tabular}{rrrrrrr}
\hline \hline \multirow{2}{*}{ Treat. } & \multirow{2}{*}{$\begin{array}{l}\text { WHC } \\
(\%)^{1)}\end{array}$} & \multirow{2}{*}{ Shear } & \multicolumn{5}{c}{ CIE color $(\mathrm{N})$} & \multicolumn{1}{c}{$\mathrm{L}^{*}$} & \multicolumn{1}{c}{$\mathrm{a}^{*}$} & \multicolumn{1}{c}{$\mathrm{b}^{*}$} & \multicolumn{1}{c}{$\Delta E^{2)}$} \\
\hline $\mathrm{C}^{3)}$ & 86.70 & 9.48 & 54.95 & 7.92 & 9.38 & 1.80 \\
1 & 94.33 & 8.65 & 50.97 & 11.30 & 7.50 & 6.00 \\
2 & 92.64 & 10.06 & 52.22 & 6.80 & 9.22 & 2.80 \\
3 & 86.95 & 8.43 & 56.98 & 9.85 & 9.22 & 2.83 \\
4 & 85.64 & 10.05 & 52.12 & 9.68 & 8.90 & 3.37 \\
5 & 92.97 & 8.11 & 59.53 & 7.95 & 11.14 & 4.50 \\
6 & 86.55 & 8.55 & 55.52 & 7.88 & 10.50 & 1.49 \\
7 & 90.27 & 10.03 & 62.06 & 7.88 & 12.44 & 7.76 \\
8 & 89.30 & 9.49 & 58.26 & 12.02 & 9.80 & 5.46 \\
9 & 90.53 & 9.55 & 60.82 & 10.52 & 11.23 & 6.75 \\
10 & 90.19 & 9.70 & 58.88 & 10.55 & 10.38 & 5.06 \\
11 & 88.28 & 9.03 & 60.52 & 11.50 & 11.15 & 7.22 \\
12 & 89.65 & 9.68 & 59.33 & 9.92 & 10.60 & 5.14 \\
13 & 90.19 & 9.34 & 59.78 & 10.67 & 10.68 & 5.85 \\
14 & 87.69 & 9.65 & 59.84 & 13.22 & 10.12 & 7.62 \\
15 & 77.45 & 7.68 & 66.68 & 10.70 & 12.80 & 12.57 \\
16 & 87.18 & 9.63 & 67.32 & 10.48 & 13.44 & 13.30 \\
17 & 79.54 & 8.22 & 68.02 & 9.25 & 13.12 & 13.56 \\
18 & 88.33 & 8.07 & 68.85 & 12.18 & 11.82 & 14.81 \\
19 & 88.79 & 9.84 & 70.68 & 10.48 & 13.45 & 16.46 \\
20 & 86.43 & 9.25 & 71.52 & 14.78 & 11.42 & 18.14 \\
\hline
\end{tabular}

${ }^{1)} \mathrm{WHC}$, water-holding capacity

${ }^{2)} \Delta E$, total color difference

${ }^{3)} \mathrm{C}$, Fresh control

with the exception of shear force $\left(R^{2}=0.50\right)$. The low $R$ square value of shear force may be attributable to the poor effects on meat tenderization that resulted from the combination of pressure and temperature settings used in this study (Hong et al., 2005; Macfarlane et al., 1981).

\section{Water-holding capacity}

Fig. 1 shows the contour maps for the WHC of pork meat. The combined use of relatively low temperature $\left(\sim 12.5^{\circ} \mathrm{C}\right)$ and elongated holding time effectively decreased the WHC of the pork sample. In these conditions, alternately, the WHC of pork increased with increasing pressure levels $(>200 \mathrm{MPa})$. In contrast, higher temperatures decreased WHC even when a short holding time was applied, and the decrease in WHC was proportional to pressure level. The optimal temperature tended to decrease with increasing pressure. The regression model demonstrated that pressure and temperature imparted significant linear $(p<$ $0.05)$ and quadratic $(p<0.001)$ effects, respectively, on WHC. However, all independent variables exhibited significant interaction terms $(p<0.05)$. Wada and Ogawa (1996) reported that the WHC of sardines was $37.1 \%$ in the original non-treated sample, but decreased to $33.5 \%$ 
Table 3. Regression coefficients for 6 dependent variables of pressurized pork

\begin{tabular}{|c|c|c|c|c|c|c|c|}
\hline \multicolumn{2}{|c|}{ Term $^{1)}$} & WHC & Shear force & $\mathrm{L}^{*}$ & $a^{*}$ & $b^{*}$ & $\Delta E$ \\
\hline Intercept & $\beta_{0}$ & 98.08 & 9.12 & 44.94 & 4.51 & 6.06 & 1.78 \\
\hline \multirow{3}{*}{ Linear } & $\beta_{1}$ & $-0.07 *$ & 0.01 & $0.07 * * *$ & -0.02 & $0.06^{* * *}$ & $-0.04 * * *$ \\
\hline & $\beta_{2}$ & -0.19 & 0.03 & $0.17 * * *$ & $0.14 * *$ & 0.04 & $0.26^{* * *}$ \\
\hline & $\beta_{3}$ & 0.20 & -0.01 & $-0.15^{* * *}$ & $0.28^{* * *}$ & $-0.13 * * *$ & $-0.17^{*}$ \\
\hline \multirow{3}{*}{ Quadratic } & $\beta_{11}$ & $0.12 \times 10^{-3}$ & $-0.25 \times 10^{-4} *$ & $0.13 \times 10^{-3} * * *$ & $0.10 \times 10^{-3 * *}$ & $-0.63 \times 10^{-4}$ & $0.36 \times 10^{-3 * * *}$ \\
\hline & $\beta_{22}$ & $-2.13 \times 10^{-3}$ & $-0.33 \times 10^{-3}$ & $-2.31 \times 10^{-3 * * *}$ & $-1.37 \times 10^{-3 *}$ & $-0.15 \times 10^{-3}$ & $-3.26 \times 10^{-3 * * * *}$ \\
\hline & $\beta_{33}$ & $-1.01 \times 10^{-3 * * *}$ & $-0.72 \times 10^{-3} *$ & $8.69 \times 10^{-3} * * *$ & $4.11 \times 10^{-3} * * *$ & $3.85 \times 10^{-3} * * *$ & $5.48 \times 10^{-3} * * *$ \\
\hline \multirow{3}{*}{ Interaction } & $\beta_{12}$ & $1.01 \times 10^{-3} *$ & $0.36 \times 10^{-4}$ & $0.14 \times 10^{-3}$ & $0.10 \times 10^{-3}$ & $-0.25 \times 10^{-3} * * *$ & $0.12 \times 10^{-3}$ \\
\hline & $\beta_{13}$ & $-9.13 \times 10^{-3 *}$ & $0.18 \times 10^{-4}$ & $-1.29 \times 10^{-3 * * *}$ & $-0.10 \times 10^{-3}$ & $-0.42 \times 10^{-3} * * *$ & $-0.39 \times 10^{-3}$ \\
\hline & $\beta_{23}$ & $8.66 \times 10^{-3 * * *}$ & $-0.36 \times 10^{-3}$ & $0.24 \times 10^{-4}$ & $-0.69 \times 10^{-3}$ & $0.31 \times 10^{-3}$ & $-0.14 \times 10^{-3}$ \\
\hline \multicolumn{2}{|c|}{$R^{2}$} & 0.76 & 0.50 & 0.96 & 0.72 & 0.86 & 0.88 \\
\hline
\end{tabular}

${ }^{1)}$ Subscript numbers 1, 2, and 3 represent pressure, time, and temperature, respectively.

*Significant at 0.05 level

** Significant at 0.01 level

$* * *$ Significant at 0.001 level
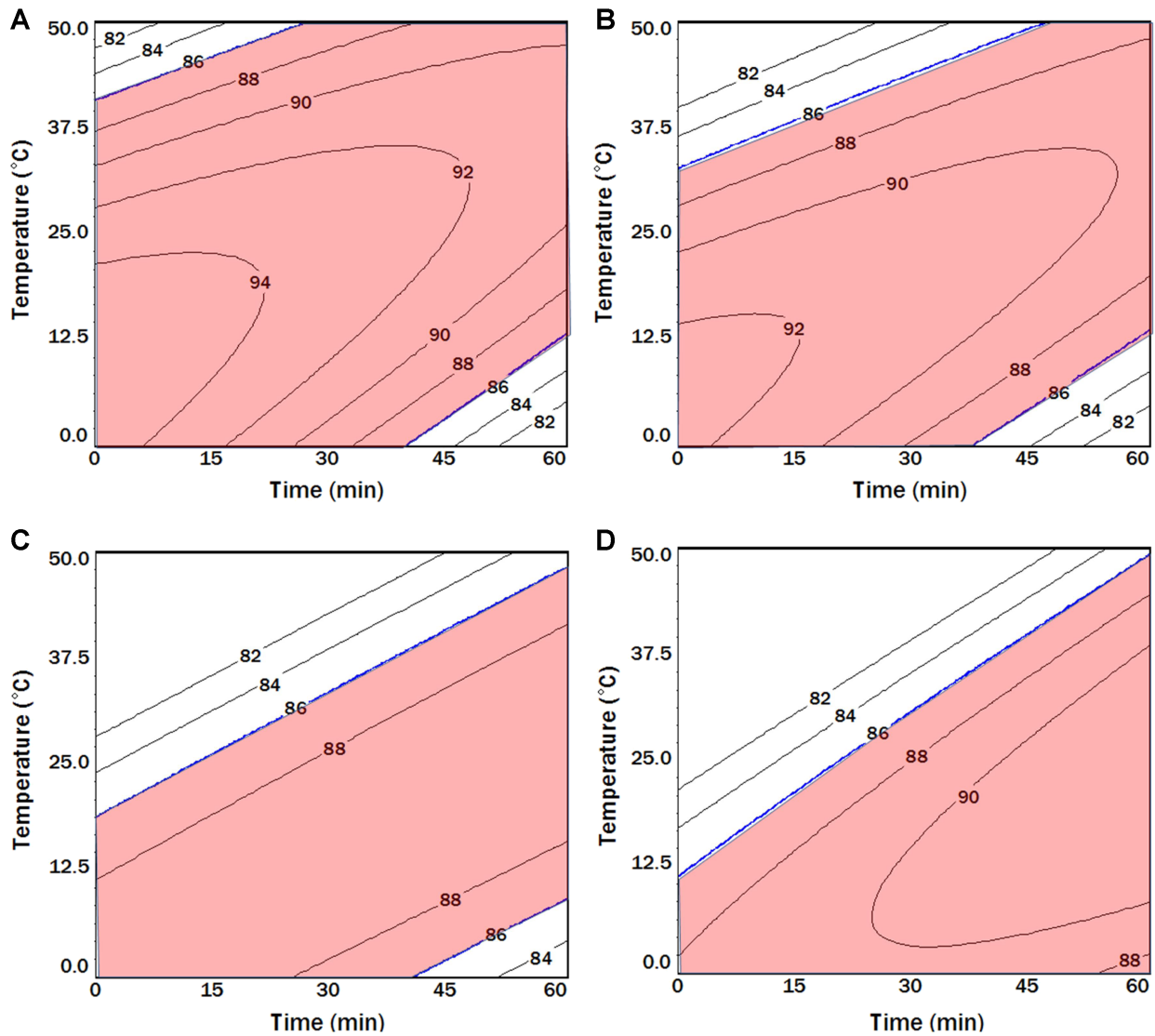

Fig. 1. Contour plots for the water-holding capacity (\%) of pork as a function of time and temperature at (A) 50, (B) 100, (C) 200, and (D) $300 \mathrm{MPa}$.

in the pressure-treated sample (200 MPa at room temperature), presumably due to protein denaturation. JimenezColménero et al. (1997) also concluded that pressure greater than $200 \mathrm{MPa}\left(6-8^{\circ} \mathrm{C}\right.$ for $\left.20 \mathrm{~min}\right)$ negatively affects the water-binding properties in fresh meat. How- ever, Hong et al. (2005) reported an increase in WHC of pork loin with increasing pressure $(200 \mathrm{MPa}$ at room temperature) and holding time $(1 \mathrm{~h})$. The improvement in WHC following pressure treatment is associated with conformational changes in protein structure, which Chef- 
tel (1992) claims can be caused by pressurization, and these changes affect protein hydration. The conformational changes that occur under high pressure are analogous to those that occur under high temperature, although some differences in protein structure have been observed. As reviewed by Knorr et al. (2006), proteins exposed to high pressure take on a reversible molten globule state, whereas heat triggers the protein to unfold irreversibly due to the breaking of covalent bonds or molecular aggregation. These findings indicate that heat and pressure induce substantially different denaturation mechanisms. In aqueous solutions, pressure treatment results in protein conformational changes at the tertiary and quaternary levels. However, pressure imparted no effects on covalent bonding. The secondary structure also appeared incompressible since $\alpha$-helix and $\beta$-sheet structures rarely are affected (Balny and Masson, 1993; Heremans and Smeller, 1998; Knorr et al., 2006). The conformational changes in protein structure are due to different types of unfolding and interaction. At high temperatures, protein molecules are destabilized by the transfer of non-polar hydrocarbons from the hydrophobic core to the outer portion of the protein molecule. However, pressure-induced denaturation results from hydration (in contrast to temperature). The pressure acts as a driving force that pushes water into the interior regions of the protein matrix. Therefore, the molecule unfolds as a result of contact loss between the nonpolar domain groups (Boonyaratanakornkit et al., 2002; Knorr et al., 2006; Priev et al., 1996; Smeller, 2002). Thus, pressure-induced conformational transition is due to water penetration into the protein interior (Knorr et al., 2006; Saad-Nehme et al., 2001). These conformational changes in meat protein may lead to improved WHC. According to Macfarlane (1985), pressure manifests an electrostriction effect to disrupt divalent cation-protein bonds. After the pressure is released, the protein's salt bridges would be less likely to reform because of the pressure-induced protein conformational changes. As a result, increases in WHC and protein solubility could persist after the pressure was released, in agreement with the results of this study.

\section{Shear force measurements}

Contour plots in Fig. 2 display the shear force of pork meat as a function of time and temperature at each of the designated pressure levels. Increases in temperature resulted in decreased shear force, whereas increases in holding time tended to increase shear force values if low temperatures $\left(<20^{\circ} \mathrm{C}\right)$ were used. Pressure levels as high as 200
MPa did not affect shear values; however, pressure levels of $300 \mathrm{MPa}$ resulted in shear reduction. In the regression model, the shear force of pork was affected significantly by the combined quadratic negative effect of pressure and temperature $(p<0.001)$. The linear terms and interactions between independent variables resulted in no significant effects on shear force. In the current study, however, the degree by which the shear force increased with increasing pressure level was within $1 \mathrm{~N}$ unit. These results indicate that shear force is not affected by either pressure or holding time. According to Suzuki et al. (1996), post-mortem meat tenderizes because of the muscle changes that occur during aging, i.e., weakened actin-myosin interactions, fragmentation of myofibrils into short segments due to Zline disintegration, degradation of the elastic connectin filaments, and weakening of connective tissue. However, the effects of pressure on post-mortem muscle and meat tenderization were not clear. In general, pressure levels measuring up to $300 \mathrm{MPa}$ yielded no effects on the connective tissue. Pressure-induced meat tenderization may be solely due to the improved actomyosin toughness, which is attributed to the myofibrillar protein (Suzuki et al. 1993). Macfarlane et al. (1981) examined the shear values of post-rigor bovine muscle pressurized at 150 $\mathrm{MPa}$ for $3 \mathrm{~h}$ in $0^{\circ} \mathrm{C}$ and reported that pressure treatment did not change shear values nor increase them when the muscle was in the stretched or contracted state, respectively. They also observed extensive changes, particularly in the I-band and M-line regions, and concluded that increased toughness was caused by an increased incidence of sarcomeres, in which thick filaments had been compressed onto the Z-line, thus removing the I-band as a zone of weakness. In the current study, temperature imparted greater effects on shear value than pressure. This result also was confirmed by our preliminary study (Hong et al., 2005), which showed that pressure up to 200 MPa yielded no effects on the shear force of post-rigor pork muscle even if the holding time was increased to $1 \mathrm{~h}$ at $4^{\circ} \mathrm{C}$. Bouton et al. (1977) reported that the application of pressure on the order of $100 \mathrm{MPa}$ for $2.5 \mathrm{~min}$ or longer on post-rigor muscle heated to $40-60^{\circ} \mathrm{C}$ improved the tenderness of subsequently cooked meat. The results indicate that pressure-induced tenderization of post-rigor meat requires a subsequent heat treatment. Locker and Wild (1984) also reported that pressure combined with heat treatment tenderizes post-rigor muscle only after a considerable period of time at an elevated temperature. Macfarlane (1985) summarized the mechanism that underlies meat tenderization by combined pressure and heat treat- 

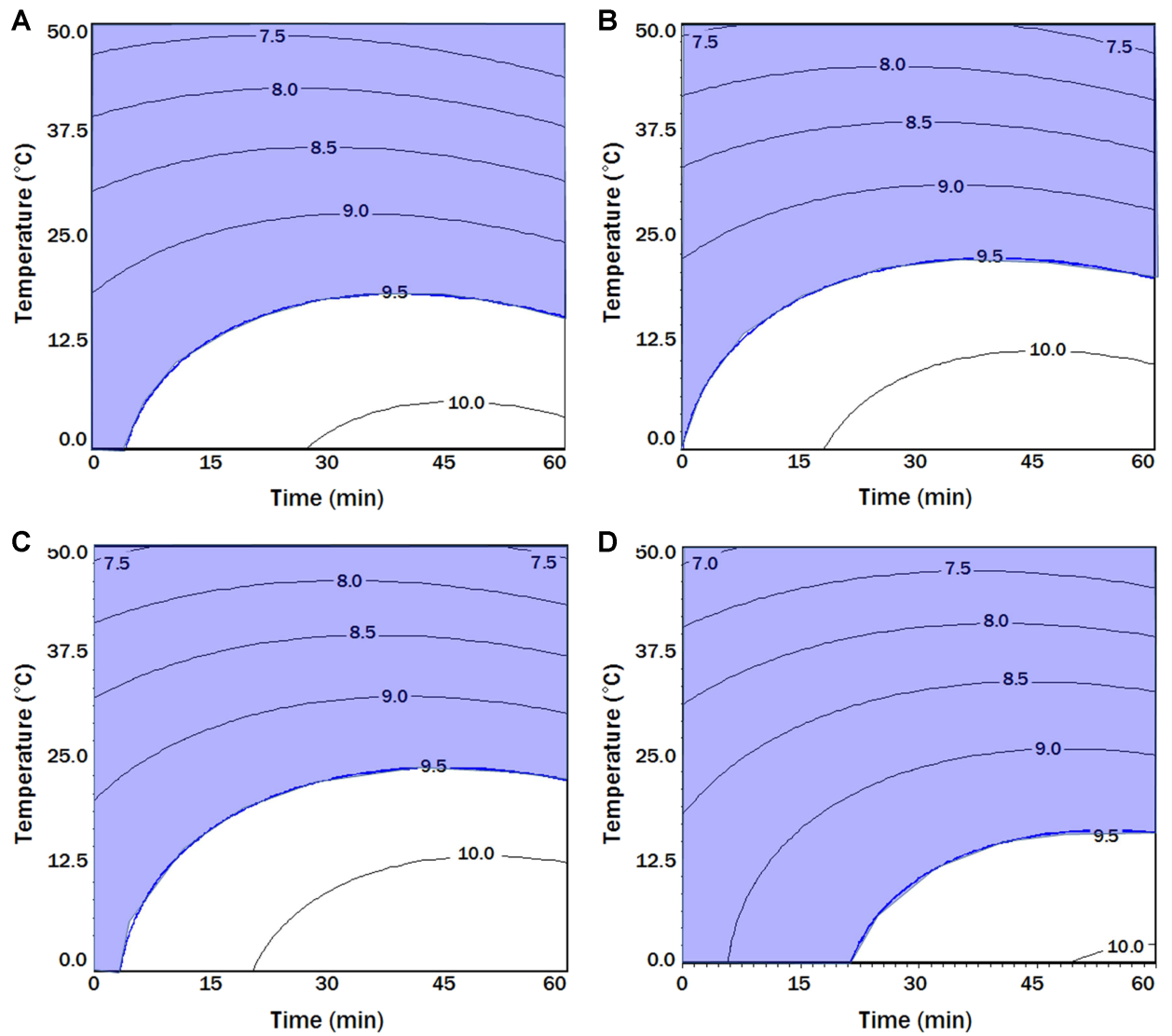

Fig. 2. Contour plots for shear force (N) of pork as a function of time and temperature at (A) 50, (B) 100, (C) 200 , and (D) 300 MPa.

ment. Associated native myofibril proteins dissociate under high pressure. The release of pressure causes proteins to associate, and thus, the pressure has no effect on meat tenderness. When heat treatment is applied subsequently, however, proteins unfold into a dissociated state. After depression and cooling, the denatured proteins are unable to associate, and therefore, meat could be tenderized. On the other hand, protein associates and denatures if heat treatment alone is applied (Macfarlane, 1985). This resulting protein state, however, cannot dissociate under high pressure, and no tenderization occurs. Consequently, the use of pressure combined with heat became an effective method to tenderize post-rigor muscle, whereas, meat with cooked-like discoloration had limited potential to be sold as fresh meat.

\section{Color}

Fig. 3 displays a contour map for the $\mathrm{L}^{*}$-value of pork. An increased holding time at a low temperature $\left(<25^{\circ} \mathrm{C}\right)$ increased the $\mathrm{L}^{*}$-value when relatively low pressure was applied $(<100 \mathrm{MPa})$; however, the effect was not significant at high temperatures. Pressure levels up to $100 \mathrm{MPa}$ showed no effect on the $\mathrm{L}^{*}$-value; however, a marked increase in the $\mathrm{L}^{*}$-value was observed for pressures above $200 \mathrm{MPa}$ under relatively high temperature condition $\left(>25^{\circ} \mathrm{C}\right)$. All independent variables showed significant linear and quadratic effects on the $\mathrm{L}^{*}$-value of pork $(p<0.001)$. Significant cross-product term also was observed between pressure and temperature $(p<0.001)$. In the current study, the model for the $\mathrm{L}^{*}$-value showed the highest $\mathrm{R}$-square value $\left(R^{2}=0.96\right)$, which clearly indicated the effects independent variables had on the lightness of pork color. On the other hand, the $\mathrm{a}^{*}$-value showed the lowest $R$-square value $\left(R^{2}=0.72\right)$ because of high variation. Maximum redness was observed at approximately $30^{\circ} \mathrm{C}$ for $40 \mathrm{~min}$ in all pressure ranges (Fig. 4). In addition, increasing pressure caused an increase in the $\mathrm{a}^{*}$-value. Temperature imparted significant linear and quadratic effects on the $\mathrm{a}^{*}$-value of pork $(p<0.001)$, whereas quadratic effects alone were imparted by pressure $(p<0.01)$. Holding time influenced both the linear $(p<0.01)$ and quadratic $(p<0.05)$ terms as well. Contour plots for the $b^{*}$ value of pork are shown in Fig. 5. An increased temperature resulted in an increased $b^{*}$-value of pork, whereas the 

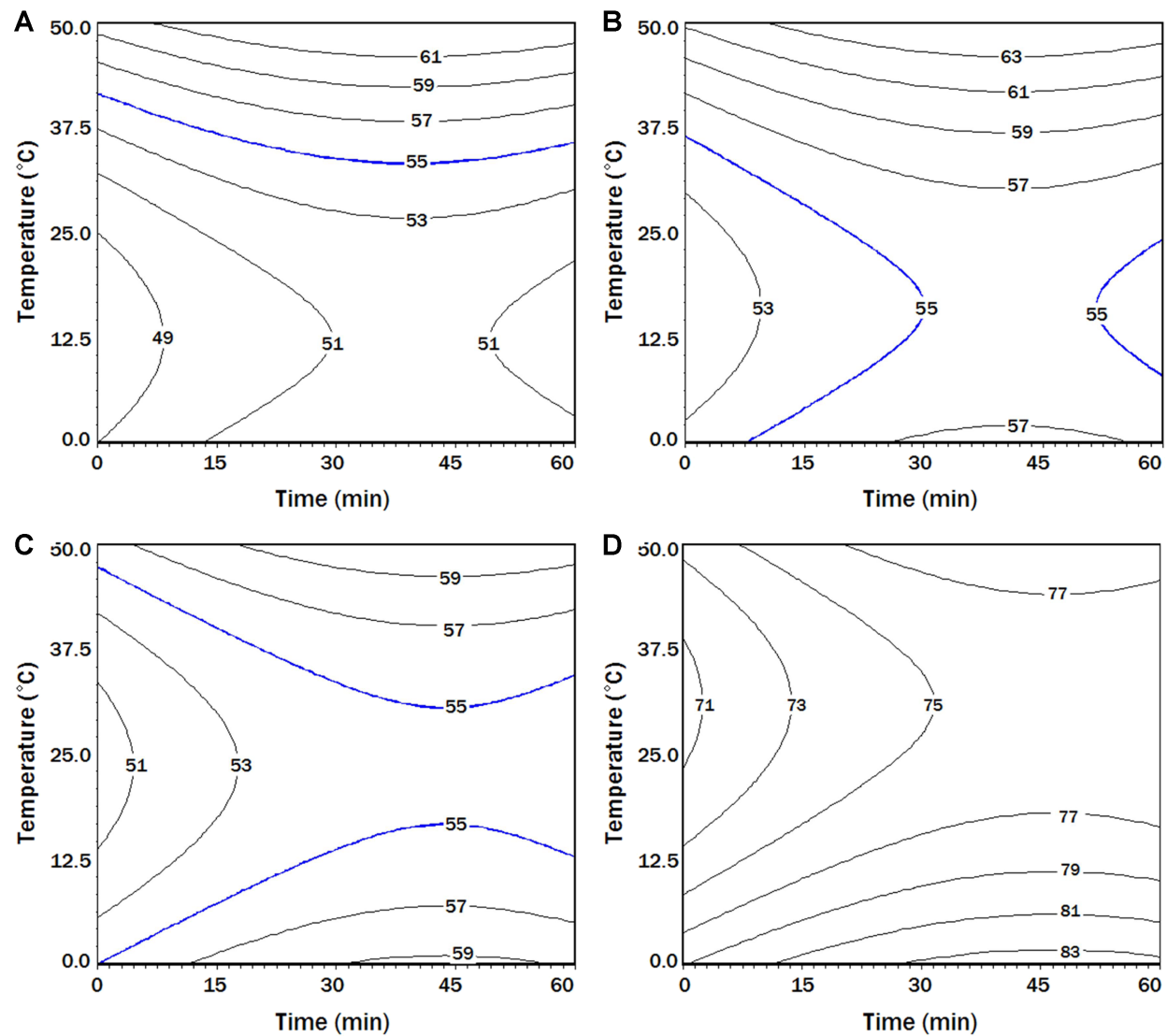

Fig. 3. Contour plots for $L^{*}$-value of pork as a function of time and temperature at (A) 50, (B) 100, (C) 200 , and (D) $300 \mathrm{MPa}$.
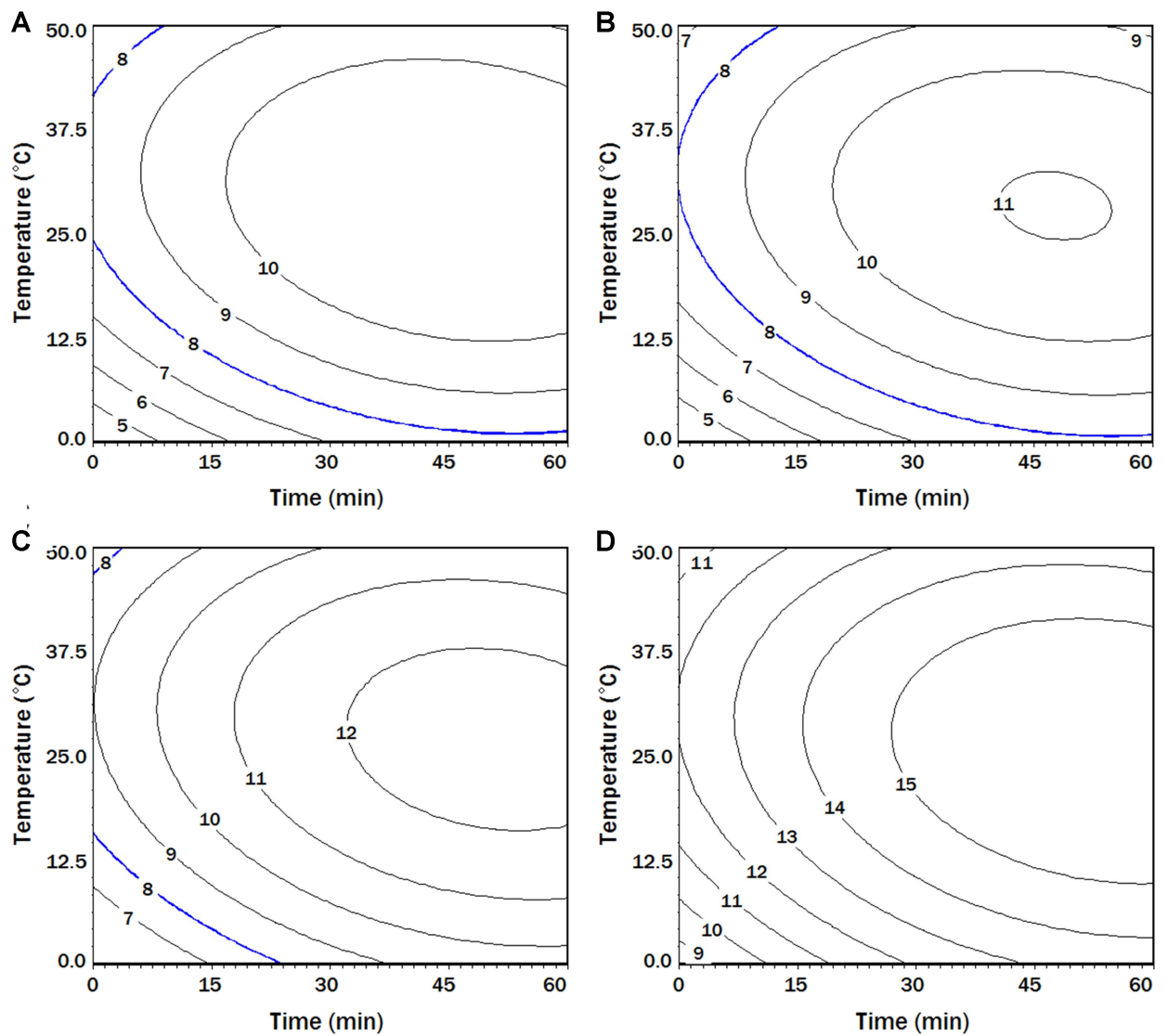

Fig. 4. Contour plots for $a^{*}$-value of pork as a function of time and temperature at (A) 50 , (B) 100, (C) 200 , and (D) $300 \mathrm{MPa}$. 
holding time effects on the $b^{*}$-value were not marked compared with temperature. An increased level of pressure increased the $b^{*}$-value of pork. In the regression model, pressure demonstrated significant linear and interaction effects on the $\mathrm{b}^{*}$-value with other parameters $(p<0.001)$. Temperature demonstrated significant linear and quadratic effects $(p<0.001)$ on the yellowness of pork. Pressureinduced discoloration was observed in other studies. Carlez et al. (1995), who investigated the color changes in minced beef due to high-pressure processing, reported that the $\mathrm{L}^{*}$-values increased significantly in the 200-350 $\mathrm{MPa}$ pressure range and the meat became pink, whereas the $\mathrm{a}^{*}$-values decreased at $400-500 \mathrm{MPa}$ and the meat became grey-brown. They concluded that the pressureinduced meat discoloration had resulted from a whitening effect in the range of 200-350 $\mathrm{MPa}$, which was due to globin denaturation and/or heme displacement or release, and oxidation of ferrous myoglobin to ferric metmyoglobin at or above $400 \mathrm{MPa}$. We also observed increasing $\mathrm{L}^{*}$-values under high-pressure treatment in our previous study (Hong et al. 2005) at levels below $200 \mathrm{MPa}$. However, heme displacement occurred above $500 \mathrm{MPa}$ (Carlez et al. 1995), and thus, the increased lightness in the current study was possibly due to denaturation of either myofibrillar protein or myoglobin (Chapleau et al. 2003). However, changes in the $\mathrm{a}^{*}$-value of meat were somewhat contradictory depending on the applied pressure conditions. Hong et al. (2005) reported increased redness of pork loin after pressurization at or below $200 \mathrm{MPa}$ for 1 h. Jung et al. (2003) observed that increases in pressure led to increases in $\mathrm{a}^{*}$-values until a pressure of about 350 $\mathrm{MPa}$ was reached, and then the $\mathrm{a}^{*}$-values decreased. They concluded that the changes in the $\mathrm{a}^{*}$-value were related to metmyoglobin content, i.e., at moderate pressure, the enzymatic system implicated in the reduction of metmyoglobin could be activated, which would lead to reductions in metmyoglobin levels. At higher pressures, the enzymatic system and the reactions involved in the formation of metmyoglobin could be disturbed by changes in the enzymatic system itself or the enzyme's environment (Jung et al., 2003). In general, meat color and color stability were related by 2 factors. A catalytic mechanism may relate to the oxygen-utilizing enzymes in meat by depleting the oxygen concentration at or near the surface, encouraging metmyoglobin formation, and activating an enzymatic reduction system that is capable of converting metmyo-
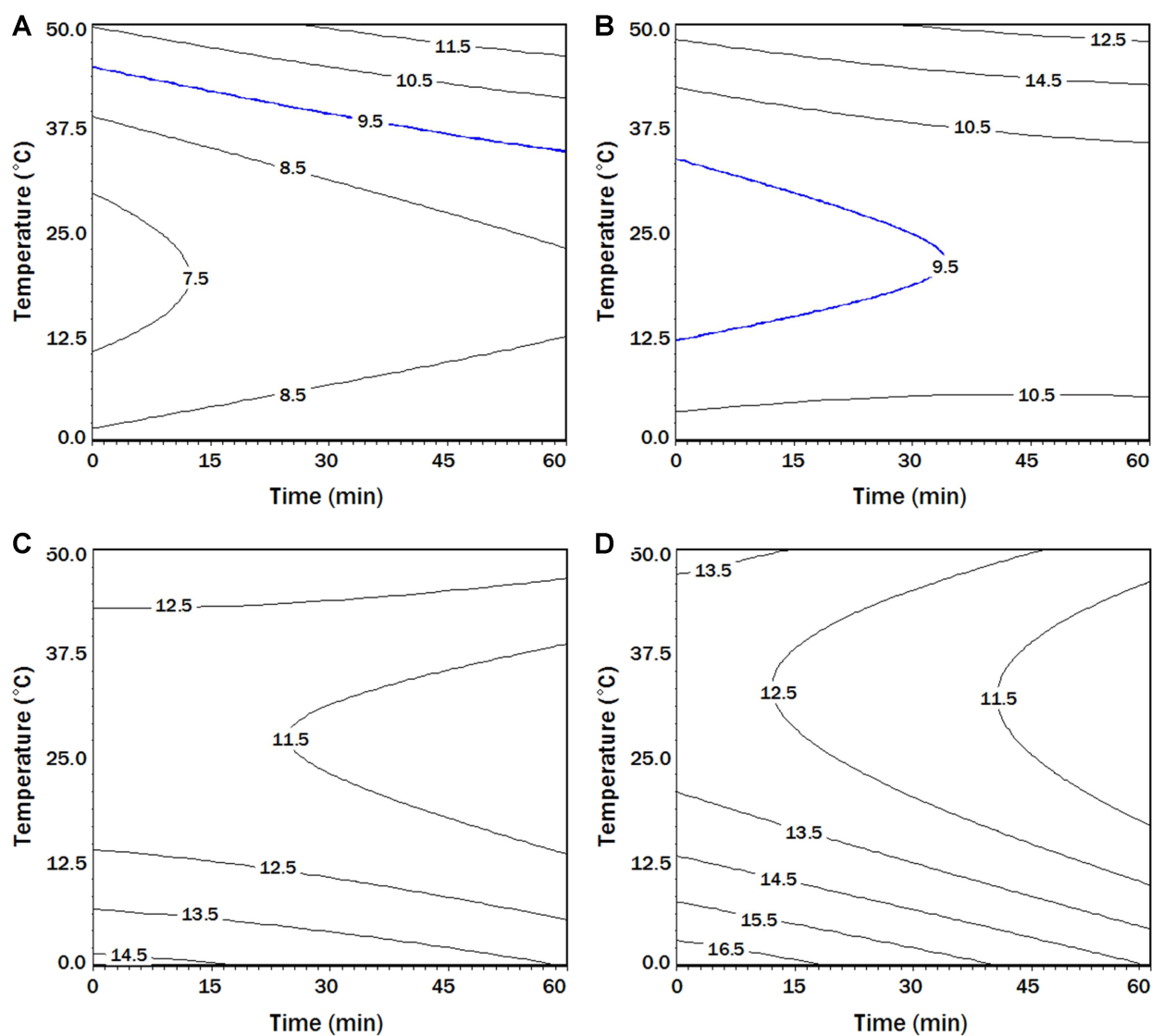

Fig. 5. Contour plots for $b^{*}$-value of pork as a function of time and temperature at (A) 50 , (B) 100, (C) 200 , and (D) $300 \mathrm{MPa}$. 
globin back to the reduced form (Ledward, 1992). Pressure-sensitive catalytic systems were disrupted under high pressure, but the metmyoglobin-reducing system remained active after the high-pressure treatment, and controlled color stability after pressurization (Cheah and Ledward, 1997). Consequently, these results may increase the $a^{*}$-value of meat after pressurization. However, care must be taken to consider meat color after pressurization, that is, pressure below $300 \mathrm{MPa}$ increases redness and also increases lightness considerably. Therefore, total color difference was adopted to optimize meat color under high pressure (Fig. 6). The tendencies were similar to those of the $\mathrm{L}^{*}$-value. In the regression model, all parameters demonstrated significant linear and quadratic effects on total color difference $(p<0.05)$. Only regions low in independent variables showed no discoloration. Pressureinduced discoloration might be an unavoidable phenomenon.

\section{Optimization}

To optimize meat quality under high pressure, we estimated 3 factors - high WHC (>86\%), low shear force
$(<9.5 \mathrm{~N})$, and low $\Delta E$ ( $<5$ units $)-$ based on the quality scores from untreated control (Table 2). At given pressure levels, central points of superimposed ranges were selected as optimum conditions. Because the minimum $\Delta E$ values at 200 and $300 \mathrm{MPa}$ conditions were already too high, 10 and 20 units of $\Delta E$ were selected as the basis for optimization. Table 4 presents the adopted optimized treatment conditions and the comparison between predicted response and observed results. The values of the optimized parameters, i.e., holding time and temperature, decreased with increasing pressure levels, showing that pressure was the most important factor affecting meat quality relative to time and temperature. Generally, the $R^{2}$ values between the predicted responses and observed values were similar to those of models. For WHC and shear value, the pressure treatments exhibited no significant differences in control, although significantly low shear values were obtained at $50 \mathrm{MPa}(p<0.05)$. However, significant increases in the $\mathrm{L}^{*}$-value occurred with increasing pressure levels $(p<0.05)$. The results supported the conclusion that the discoloration of high-pressure-processed meat is influenced mainly by pressure, and not by the holding time or temperature.
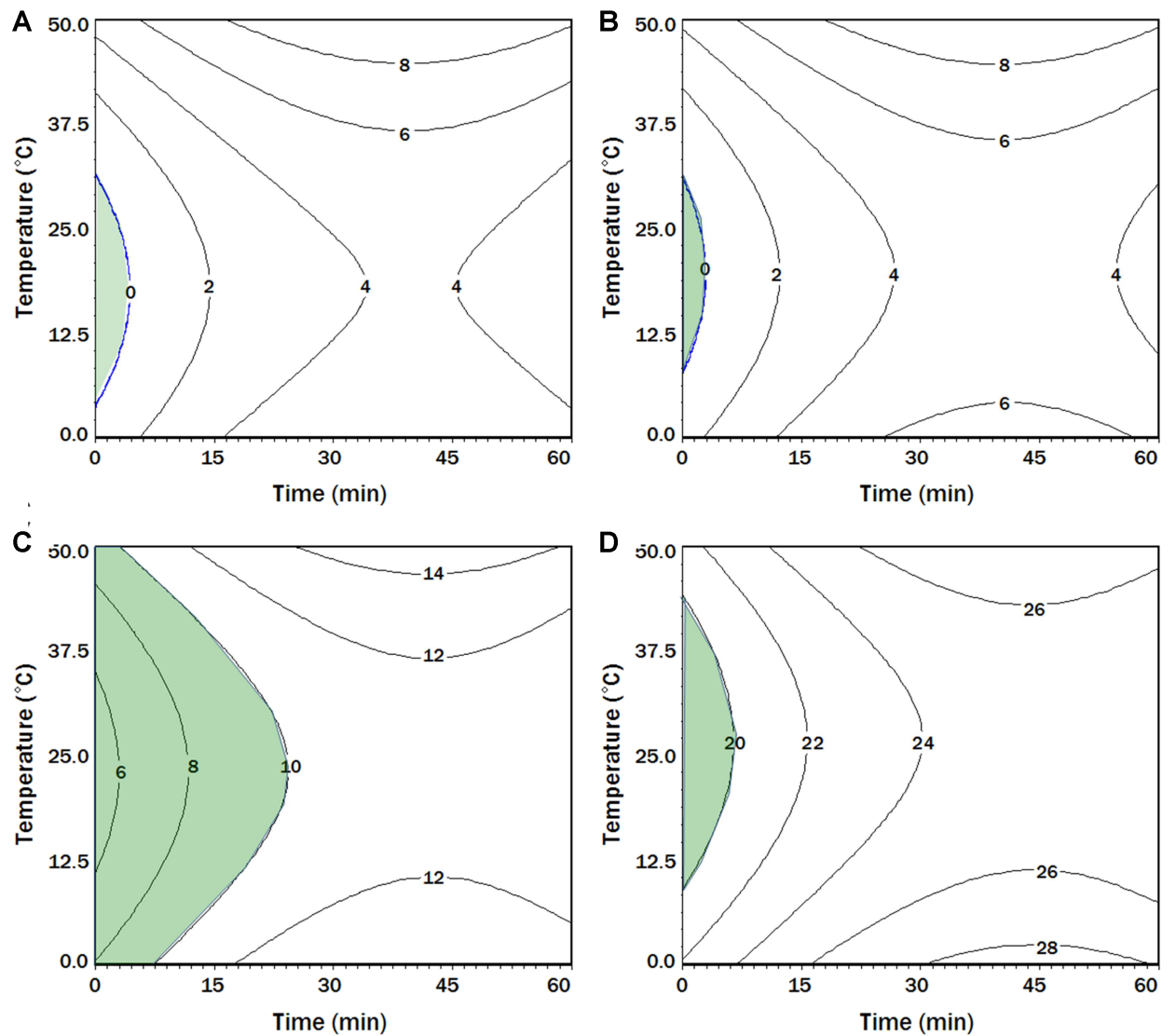

Fig. 6. Contour plots for total difference in pork color as a function of time and temperature at (A) 50, (B) 100, (C) 200, and (D) $300 \mathrm{MPa}$. 
Table 4. Optimized treatment parameters and a comparison between the predicted response and the observed result at various pressure levels

\begin{tabular}{|c|c|c|c|c|c|c|c|}
\hline & & \multirow{2}{*}{ Control } & \multicolumn{4}{|c|}{ Pressure (MPa) } & \multirow{2}{*}{$R^{2}$} \\
\hline & & & 50 & 100 & 200 & 300 & \\
\hline \multirow{2}{*}{$\begin{array}{l}\text { Optimized } \\
\text { Parameters }\end{array}$} & Time (min) & & 60 & 29 & 25 & 2 & \\
\hline & Temperature $\left({ }^{\circ} \mathrm{C}\right)$ & & 38 & 31 & 26 & 14 & \\
\hline \multirow{2}{*}{$\begin{array}{l}\text { Water holding } \\
\text { capacity }(\%)\end{array}$} & $Y_{\mathrm{P}}^{1)}$ & 86.70 & 91.00 & 90.13 & 87.60 & 85.60 & \multirow{2}{*}{0.72} \\
\hline & $Y_{\mathrm{o}}^{2)}$ & $87.26^{\mathrm{ab}}$ & $89.17^{\mathrm{a}}$ & $89.10^{\mathrm{a}}$ & $85.83^{b}$ & $87.88^{\mathrm{a}}$ & \\
\hline \multirow{2}{*}{$\begin{array}{l}\text { Shear force } \\
\text { (N) }\end{array}$} & $Y_{\mathrm{P}}$ & 9.48 & 7.99 & 9.00 & 9.28 & 8.67 & \multirow{2}{*}{0.50} \\
\hline & $Y_{\mathrm{o}}$ & $9.27^{\mathrm{a}}$ & $8.16^{\mathrm{b}}$ & $9.20^{\mathrm{a}}$ & $9.36^{\mathrm{a}}$ & $8.85^{\mathrm{a}}$ & \\
\hline \multirow{2}{*}{ CIE L* } & $Y_{\mathrm{P}}$ & 54.95 & 55.93 & 56.85 & 63.81 & 73.44 & \multirow{2}{*}{0.80} \\
\hline & $Y_{\mathrm{o}}$ & $55.20^{\mathrm{e}}$ & $59.42^{\mathrm{d}}$ & $63.12^{\mathrm{c}}$ & $66.17^{\mathrm{b}}$ & $70.42^{\mathrm{a}}$ & \\
\hline \multirow{2}{*}{ CIE a* } & $Y_{\mathrm{P}}$ & 7.92 & 10.48 & 10.59 & 11.53 & 11.28 & \multirow{2}{*}{0.67} \\
\hline & $Y_{\mathrm{o}}$ & $8.55^{\mathrm{c}}$ & $9.92^{\mathrm{b}}$ & $10.13^{b}$ & $12.25^{\mathrm{a}}$ & $11.83^{\mathrm{a}}$ & \\
\hline \multirow{2}{*}{ CIE b* } & $Y_{\mathrm{P}}$ & 9.38 & 9.96 & 9.78 & 11.50 & 14.31 & \multirow{2}{*}{0.85} \\
\hline & $Y_{\mathrm{o}}$ & $9.02^{\mathrm{d}}$ & $8.58^{d}$ & $9.92^{\mathrm{c}}$ & $12.43^{\mathrm{b}}$ & $14.42^{\mathrm{a}}$ & \\
\hline \multirow{2}{*}{$\begin{array}{l}\text { Total color } \\
\text { difference }\end{array}$} & $Y_{\mathrm{P}}$ & 1.80 & 4.88 & 4.88 & 10.12 & 19.73 & \multirow{2}{*}{0.86} \\
\hline & $Y_{\mathrm{o}}$ & $1.13^{\mathrm{e}}$ & $4.52^{\mathrm{d}}$ & $8.17^{\mathrm{c}}$ & $12.15^{\mathrm{b}}$ & $16.49^{\mathrm{a}}$ & \\
\hline
\end{tabular}

${ }^{1)} Y_{\mathrm{P}}$ calculated from the regression models

${ }^{2)} Y_{0}$, experimental scores

${ }^{a-e}$ Means with different superscript within same row are significantly different $(p<0.05)$.

If a 10-unit rise in total color difference is considered a significant modification to the appearance of meat color (Jung et al., 2003), pressure levels above 200 MPa may deteriorate meat's appearance. However, processed meat, in which color is not an important quality, can gain other advantages by high-pressure treatment, such as better texture and $\mathrm{WHC}$, even if $300 \mathrm{MPa}$ of pressure with higher temperature and holding time is used. Although the changes in pressurized meat color were evidenced mainly by changes in the redox state and the unfolding of myoglobin (Carlez et al., 1995), the lightness of pork after pressurization was also affected by the denaturation of myofibrillar proteins (Hector et al., 1992). Eventually, the protein stability of pork under selected optimum pressure conditions was estimated by DSC (Fig. 7). Control pork muscle samples showed 3 main endothermic peaks at $55.2^{\circ} \mathrm{C}, 64.3^{\circ} \mathrm{C}$, and $78.3^{\circ} \mathrm{C}$ that corresponded to myosin, collagen, and actin, respectively. These peak temperatures did not shift with applied pressure conditions; however, the myosin peak disappeared after pressurization at 300 $\mathrm{MPa}$, which indicated myosin denaturation. In relative enthalpy, pressurization up to $200 \mathrm{MPa}$ showed only slight changes within $0.1 \mathrm{~J} / \mathrm{g}$, while a $300-\mathrm{MPa}$ treatment reduced enthalpy by more than half of the control for collagen and actin peaks. The results indicate that of the 3 independent parameters, pressure, time, and temperature, applied to the optimization procedure, pressure level is the most significant contributor to the thermostability of

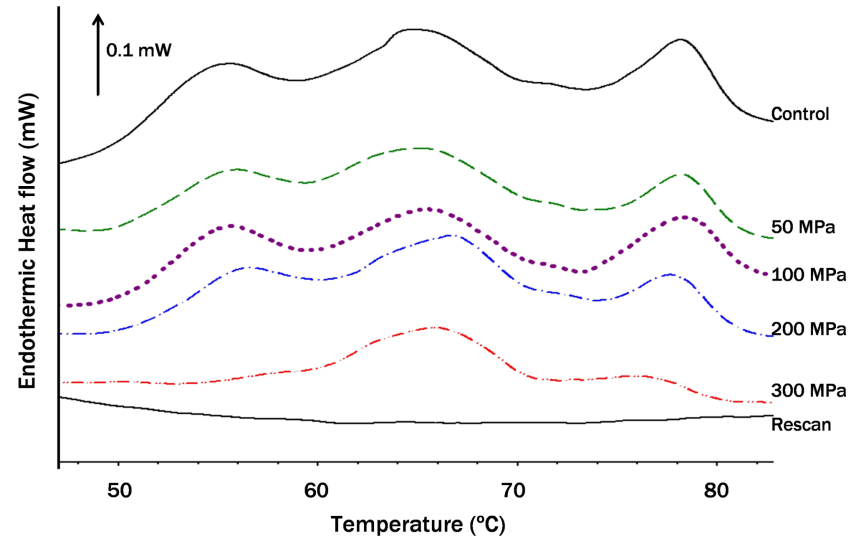

Fig. 7. Thermograms of pork treated with different pressures and then heated at a rate of $5^{\circ} \mathrm{C} / \mathrm{min}$.

meat protein. In the current study, a 300-MPa treatment was held under pressure for $2 \mathrm{~min}$ and compared to 25 min at $200 \mathrm{MPa}$; severe denaturation was observed in myosin and actin. However, the collagen peak apparently is unaffected by pressure, in agreement with the results obtained by Ma and Ledward (2004) and Suzuki et al. (1993).

\section{Acknowledgements}

This study was supported by the Brain Korea 21 Project from Ministry of Education and Human Resources Development. 


\section{References}

1. Balny, C. and Masson, P. (1993) Effects of high pressure on proteins. Food Rev. Int. 9, 611-628.

2. Boonyaratanakornkit, B. B., Park, C. B., and Clark, D. S. (2002) Pressure effects on intra- and intermolecular interactions within proteins. Biochim. Biophys. Acta 1595, 235-249.

3. Bouton, P. E., Ford, A. L., Harris, P. V., Macfarlane, J. J., and Óshea. J. M. (1977) Pressure-heat treatment of postrigor muscle: Effects on tenderness. J. Food Sci. 42, 132-135.

4. Carlez, A., Veciana-Nogues, T., and Cheftel, J. C. (1995). Changes in colour and myoglobin of minced beef meat due to high pressure processing. Lebensm. Wiss. u. Technol. 28, 528-538.

5. Chapleau, N., Mangavel, C., Compoint, J. P., and de Lamballerie-Anton, M. (2003). Effect of high pressure processing on myofibillar protein structure. J. Sci. Food Agric. 84, 66-74.

6. Cheah, P. B. and Ledward, D. A. (1997). Inhibition of metmyoglobin formation in fresh beef by pressure treatment. Meat Sci. 45, 411-418.

7. Cheftel, J. C. (1992) Effects of high hydrostatic pressure on food constituents: An overview. In: High pressure and biotechnology. Balny, C., Hayashi, R., Heremans, K. and Masson, P. (eds.) John Libbey Eurotext Ltd, Paris, pp. 195-208.

8. Heremans, K. and Smeller, L. (1998) Protein structure and dynamics at high pressure. Biochim. Biophys. Acta 1386, 353-370.

9. Hector, D. A., Brew-Graves, C., Hassen, N., and Ledward, D. A. (1992) Relationship between myosin denaturation and the colour of low-voltage-electrically-stimulated beef. Meat Sci. 31, 299-307.

10. Hong, G. P., Park, S. H., Kim, J. Y., Lee, S. K., and Min, S. G. (2005) Effects of time-dependent high pressure treatment on physico-chemical properties of pork. Food Sci. Biotechnol. 14, 808-812.

11. Jiménez-Colmenero, F., Carballo, J., Fernández, P., Barreto, G., and Solas, M. T. (1997) High pressure induced changes in the characteristics of low-fat and high-fat sausages. J. Sci. Food Agric. 75, 61-66.

12. Jung, S., Ghoul, M., and de Lamballerie-Anton, M. (2003) Influence of high pressure on the color and microbial quality of beef meat. Lebensm. Wiss. u. Technol. 36, 625-631.

13. Knorr, D., Heinz, V., and Buckow, R. (2006) High pressure application for food biopolymers. Biochim. Biophys. Acta 1764, 619-631.

14. Ledward, D. A. (1992) Colour of raw and cooked meat. In: The chemistry of muscle-based foods. Johnston, D. A., Knight, M. K. and Ledward, D. A. (eds.) The Royal Society of Chemistry, Cambridge, pp. 128-144.

15. Locker, R. H. and Wild, D. J. C. (1984) Tenderisation of meat by pressure-heat involves weakening of the gap filaments in the myofibril. Meat Sci. 10, 207-233.

16. Ma, H. J. and Ledward, D. A. (2004) High pressure/thermal treatment effects on the texture of beef muscle. Meat Sci. $\mathbf{6 8}$, 347-355.

17. Macfarlane, J. J. (1985) High pressure technology and meat quality. In: Developments in meat science. Lawrie, R. (ed.) Elsevier Applied Science Publishers, NY, Vol. 3, pp. 155-184.

18. Macfarlane, J. J., McKenzie, I. J., Turner, R. H. and Jones, P. N. (1981) Pressure treatment of meat: Effects on thermal transitions and shear value. Meat Sci. 5, 307-317.

19. Mancini, R. A. and Hunt, M. C. (2005) Current research in meat color. Meat Sci. 71, 100-121.

20. Priev, A., Almagor, A., Yedgar, S., and Gavish, B. (1996) Glycerol decreases the volume and compressibility of protein interior. Biochem. 35, 2061-2066.

21. Saad-Nehme, J., Silva, J. L., and Meyer-Fernandes, J. R. (2001) Osmolytes protect mitochondrial $\mathrm{F}_{0} \mathrm{~F}_{1}$-ATPase complex against pressure inactivation. Biochim. Biophys. Acta 1546, 164-170.

22. Smeller, L. (2002) Pressure-temperature phase diagrams of biomolecules. Biochim. Biophys. Acta 1595, 11-29.

23. Suzuki, A., Kim, K., and Ikeuchi, Y. (1996) Understanding the pressure effects on postmortem muscle. In: High pressure bioscience and biotechnology. Hayashi, R. and Balny, C. (eds.) Elsevier Science, Amsterdam, Vol. 13, pp.289-298.

24. Suzuki, A., Watanabe, M., and Ikeuchi, Y. (1993) Effects of high-pressure treatment on the ultrastructure and thermal behaviour of beef intramuscular collagen. Meat Sci. 35, 1725.

25. Wada, S. and Ogawa, Y. (1996) High pressure effects on fish lipid degradation: Myoglobin change and water holding capacity. In: High pressure bioscience and biotechnology. Hayashi, R. and Balny, C. (eds) Elsevier Science, Amsterdam, Vol. 13, pp. 351-356.

(Received 2012.3.3/Revised 2012.4.29/Accepted 2012.5.1) 